\title{
Analysis of Data on Adverse Drug Events Reported to the Food and Drugs Administration of the United States of America
}

\author{
Emmanuel M. Baah \\ Faculty of Applied Sciences, Takoradi Technical University, Takoradi, Ghana \\ Email:emmanuel.baah@ttu.edu.gh
}

How to cite this paper: Baah, E.M. (2020) Analysis of Data on Adverse Drug Events Reported to the Food and Drugs Administration of the United States of America. Open Journal of Statistics, 10, 203-227. https://doi.org/10.4236/ojs.2020.102015

Received: January 2, 2020

Accepted: March 31, 2020

Published: April 3, 2020

Copyright $\odot 2020$ by author(s) and Scientific Research Publishing Inc. This work is licensed under the Creative Commons Attribution-NonCommercial International License (CC BY-NC 4.0). http://creativecommons.org/licenses/by-nc/4.0/ (c) (i) (s) Open Access

\begin{abstract}
Background: The Spontaneous Reporting System (SRS) of the Food and Drugs Administration (FDA) of the United States of America (US), known as the FDA Adverse Event Reporting System (FAERS), is a mechanism for collecting information on safety concerns associated with the use of drugs for redress, as they are used on large scale. The data which is the subject of this paper came from the FAERS database. This paper reports on the analysis of data covering 2013 to 2018 period, but compares the observed trends in the variables during this period with that of the 2007 to 2012 period to ascertain whether the trends change over time; as this paper is, in a sense, a sequel to an earlier one with a similar title as this but covering the period 2007 to 2012 . Objectives: The objectives of the study reported in this paper were to: i) explore the trends in the variables involved with the adverse events problem in the 2013 to 2018 period and compare these trends with that found in the study covering the 2007 to 2012 period; ii) determine whether or not the level of missing variable values in the 2013 to 2018 period is lower than, the same or higher than it was in the 2007 to 2012 period; iii) find out how the first twenty principal suspect drugs most cited to be involved in adverse events occurring during drug use in the 2013 to 2018 period compare with that of the 2007 to 2012 period. Methods: The Food and Drugs Administration (FDA) makes extracts from the FAERS database freely available to the public on quarterly basis. Fourteen (14) out of over fifty (50) variables contained in these extracts were reckoned to be connected with the objectives of the study and were examined using the tools of frequencies, proportions and averages, on account of the nature of the data. Results: For the period 2013 to 2018, adverse events reports submitted to the FDA (US) more than doubled (2.1 times), accounting for an annual average growth rate of $15.8 \%$, which is considerably lower than the annual average growth rate of $22.1 \%$ for the 2007 to 2012 period.
\end{abstract}


However, the reported number of cases for 2015 was $53.8 \%$ more than that of 2014. Consistent with the results for 2007 to 2012 period, the 2013 to 2018 period saw Female subjects accounting for over $60 \%$ of the annual and the overall number of reports. Overall, non-health professionals appear to have a slight edge over health professionals in reporting adverse drug events in the 2013 to 2018 period, with an indication that reports from non-health professionals are on the decline and that from health professionals is on the rise. Non-health professionals and health professionals were almost equally likely to report adverse events in the 2007 to 2012 period. Also, the findings for the 2013 to 2018 period suggest that the older one gets the more vulnerable one becomes to adverse events associated with drug use, which is consistent with the findings for the 2007 to 2012 period. Conclusion: The dangers that come with the use of drugs is an evolving one and therefore there is the need to examine SRS data from time to time so that emerging drug safety concerns can be dealt with timeously.

\section{Keywords}

Drugs, Adverse Drug Events (ADEs), Adverse Drug Reactions (ADRs), Spontaneous Reporting System (SRS)

\section{Introduction}

The unwanted effects of drugs, known commonly as side-effects and technically as Adverse Drug Reactions (ADRs), are not always discovered at the development stage of drugs [1] [2] [3] [4]. Collection of data on Adverse Drug Events (ADEs) is helpful in not only detecting ADRs that are yet to be uncovered but are also key in understanding changes in the adverse reaction profile of drugs as they become widely used for both intended and unintended purposes [5] [6]. The collection of data on adverse events associated with the use of drugs is done through a mechanism referred to as the Spontaneous Reporting System (SRS) [1] [7] [8]. The SRS of the Food and Drugs Administration (FDA) of the United States of America (US) is known as FDA Adverse Event Reporting System (FAERS) [1]. It allows the FDA to expeditiously deal with drug safety concerns that could result in death, irreversible bodily harm or some other serious outcome. Spontaneous reporting systems are part of a wider machinery called pharmacovigilance, which is concerned with tracking the use of drugs and associated adverse experiences to detect irregularities in their use, bona fide harms related to them which are hitherto unknown and changes in their adverse reaction profiles as they are publicly available for use; so that remedial measures could be taken if warranted [5] [8] [9] [10].

Spontaneous reporting systems are plagued by a number of problems. These problems include the under-reporting of adverse events [9] [11] and instability in the reporting rate; it is thought to be subject to media hype of episodes of adverse events and the marketing activities of pharmaceutical concerns, leading to 
uneven periods of increased reporting by an overly sensitive public, some of which are spurious adverse events. Reporting requirements regarding serious and uncommon events could unduly influence the reporting of these kinds of events, as reporting institutions are expected to pay particular attention to them [9] [11] [12] [13]. Other problems SRSs are identified with comprise partial or erroneous reporting, which affects such variables as dose, suspect drugs, indication, cotherapy, age and gender amongst others [12] [13]. Also reporting conventions and practices differ from country to country and from institution to institution [9] [12] [13]. The different stakeholders in a case of adverse event are free to report on their own and old cases may be taken as new, leading to duplicate reports if they are not properly tracked [1] [13] [14]. The user population of a drug cannot be accurately determined at any point in time.

The problems recounted above makes the determination of incidence rate and prevalence rate of adverse reactions impossible [9] [11] [12], and whether or not a medication is the causative agent of an adverse event that occurred during its use is something that can only be determined through a rigorous causality assessment by experts, taking into consideration the prevailing circumstances during the use of the medication and not based on the fact that the event occurred at the time the drug was being used alone.

Notwithstanding the problems enumerated above, SRS data has been instrumental in the discovery of adverse drug reactions and other irregularities in the use of drugs, which would have been difficult or taken time to find without it. [5] [6] [13]. The relationship between Tramadol and the side effect of addiction and seizures and the link between Felbamate and aplastic anaemia are two of many examples [6]. Suffice it to say there are a number of texts [1] [8] [9] [10] [15] that discuss spontaneous reporting systems and the broader field of pharmacovigilance.

The study reported in this paper was intended to identify and describe the trends in the variables associated with the problem of adverse events in medication use during the 2013 to 2018 period and to compare them with that of the 2007 to 2012 period [16], particularly whether the transition from an old system of organising the data to a new one by the FDA (US) has had any effect on the trends observed in the variables. Specifically, the objectives of the study were to: i) explore the trends in the variables involved with the adverse events problem in the 2013 to 2018 period and compare these trends with that found in the study covering the 2007 to 2012 period; ii) determine whether or not the level of missing variable values in the 2013 to 2018 period is lower than, the same or higher than it was in the 2007 to 2012 period; iii) find out how the first twenty principal suspect drugs most cited to be involved in adverse events occurring during drug use in the 2013 to 2018 period compare with that of the 2007 to 2012 period.

The rest of the paper is organised as follows: Section 2 explains the nature of the data, how it was processed and the tools used in the analysis. Section 3 presents the results of analysis of data covering the 2013 to 2018 period with some initial 
discussion. Section 4 presents a discussion of the findings for the 2013 to 2018 period in full, and compares the findings with that of the 2007 to 2012 period [16]. Some thoughts on the implications of the findings for pharmacovigilance form the concluding section, Section 5 .

\section{Methods}

\subsection{Data: Nature and Processing}

The FDA makes available on its website anonymised quarterly extracts of data on adverse drug events from the FAERS database [14]. The analysis reported in this paper used quarterly extracts covering the period from 2013 to 2018. They were downloaded between October 1, 2018 and May 27, 2019. There are seven ASCII (American Standard Code for Information Exchange) data files together with their metadata (explanatory notes on the attributes of the seven data files and the variables they hold) in each quarterly extract. Altogether, the seven data files: Demographic, Drugs, Reaction, Outcome, Report Source, Therapy and Indication contain over fifty (50) variables (inclusive of link or key variables) [17]. Fourteen (14) of these variables were examined as they relate to the objectives of the study.

Duplicate records relating to the same subjects were removed leaving only the latest version of the adverse event reports, which are the most up-to-date [17]. Reports of adverse events occurring in studies, literature or coming from outside the United States were excluded because they may not fit the description of "spontaneous" or may not meet the inclusion criteria for reports originating from within the US. Their exclusion ensures that the remaining data is as homogeneous as possible, as these reports may represent additional sources of variation [18].

Some of the variables that are in the Drug, Reaction and Outcome files are "multiple response" in nature-the values they can assume are not mutually exclusive. For example if a subject of an adverse drug event suffered a disability, was hospitalised and died as a result of the adverse event, then there would be three values for the variable Outcome for this subject: namely Disability, Hospitalisation and Death [17]. The sum of the percentages corresponding to the values such variables can assume is expected to be more than $100 \%$ as one is compelled to dichotomise as death and all other outcomes or hospitalisation and all other outcomes, as in the above instance.

Three types of reports are submitted to the FDA: expedited, periodic and direct. Adverse drug experiences that are serious and not "expected" (not captured in the product information- "not been previously observed" [19]) are required to be reported to the FDA within fifteen (15) days by the manufacturer or packer or distributer (sponsors) of the prescription drug product in question. Reports of this sort are called expedited reports [19]. Reports required of sponsors on adverse drug experiences that are non-expedited are referred to periodic reports. Reports that are submitted to the FDA without recourse sponsors on a voluntary basis are known as direct reports [14] [19]. 
The age of a subject of an adverse can be expressed in decades, years, months, weeks, days and hours [17]. Indeed some of the ages were expressed in minutes. Values of age expressed in units other than years were converted to years, and age was then recoded into four groups: 0 - 17, 18 - 44, 45 - 64, and 65 and over, so that one could compare the active group with the non-active group.

In reporting an adverse event, one is required to indicate female with $\mathrm{F}$ and male with M. The codes UNK and NS are used in situations where the sex of the subject is unknown (cannot be determined, as in a fetus) or was not specified respectively [17]. The sex values UNK and NS were recoded as missing for the purposes of this study.

As is common with secondary data and recounted above, SRS data come with some challenges, for which the FAERS data is no exception [6] [12] [13] [17]. Indeed a sizable portion of some of the subjects reported on in this paper have missing values for some of the variables. However the value of the data in terms of the insight it could provide is not in doubt [5] [6] [13] and its analysis is useful in appreciating the issues concerning irregularities linked with drug use [20].

While the study could have looked at the data for the period 2007 to 2018 in one go, it looked at the data for the 2007 to 2012 period separately from that of the 2013 to 2018 for two reasons: Firstly, the FDA reorganised the adverse event database during the last quarter of 2012, so the way the adverse event reports were treated before and after this point in time are not the same-the new adverse event reporting system (known as the FDA Adverse Event Reporting System, FAERS) is Case/Version-based while the old adverse event reporting system (now known as the Legacy Adverse Event Reporting System, LAERS) was Individual-Safety-Report (ISR)-based [14], so duplicates reports of the same adverse event episode are supposed to be relatively easy to identify under the current system. Secondly, it allows us to determine whether or not the reorganisation has had any significant effect on the trends in the variables associated with the problem of adverse effects in drug use by comparing the trends in the variables before the reorganisation with that after the reorganisation.

\subsection{Tools}

The statistics used to unravel the information held by the data are the frequencies, proportions and averages owing to the nature of the data. The geometric mean was used to find the averages of the variables on account of two reasons: i) it is suitable for finding the averages of percentages, growth rates, ratios, indexes or quantities that change over time and ii) compared to the arithmetic mean, the geometric mean is relatively better at reining in the effect of extreme values on the value of the mean [21]. Given a set of $n$ positive values $x_{1}, x_{2}, \cdots, x_{n}$, the geometric mean GM is given by

$$
G M=\left(x_{1} \cdot x_{2} \cdot x_{3} \cdots \cdot x_{n-1} \cdot x_{n}\right)^{1 / n}
$$

Because of what appears to be a lack of a clear (probability) structure and the probable high level of noise associated with SRS data, arising from the problems 
enumerated in the introduction and the primary purpose for the collection of the data, analyses of SRS data have focused more on using data mining approaches in finding hitherto unknown adverse drug reactions and other irregularities associated with the use of drugs. By the same token the current study did not apply any of the less mundane statistical approaches, such as time series, regression et cetera to the data. A hierarchical Bayesian method for sifting SRS data for unknown adverse drug reactions has been explored and it is the intention to report on it separately owing to the volume of material involved and the focus of the work.

Three software were used to process the data: the R [22], the SAS [23] and the MS Excel [24]. As noted above, the variables are contained in several files and some of them can assume more than one value concurrently. Therefore, one needs a database management software or a software with SQL capability to be able to transform the data, define multiple response sets and analyse the data; the SAS software was helpful in this respect. The R software was mainly used to render the graphics and MS Excel was used to compute the averages of the variables.

\section{Results of Analysis}

\subsection{Trend in the Number of Reports over Time}

The number of adverse events reports received annually by the FDA (US) for the 2013 to 2018 period more than doubled (2.1 times) from 746,182 in 2013 to $1,554,866$ in 2018 (Table 1), excluding reports from foreign sources, studies or occurring in the literature. This translates to an average growth rate of $15.8 \%$ annually, with the cumulative total number of reports for the period under consideration standing at $6,714,463$. However there was a sharp rise in the number of reports submitted in 2015, accounting for $53.8 \%$ increase over the number of reports submitted in 2014, with the total number of reports received in 2016 representing a drop of approximately $4.4 \%$ relative to that of 2015 . The trend in the number of reports submitted annually per one million inhabitants for the period under consideration is as shown in Figure 1. The increasing trend over time, presented by the figure, is suggestive of a faster growth rate of the number of reports submitted annually relative the growth rate of the US population. However the figure seems to confirm the earlier observation that there was a drop in the total number of reports received in 2016 relative to that of 2015, as the mark indicating the 2016 value is manifestly lower than the mark indicating the 2015 value (one is reminded though that each of the values used to plot the graph is a ratio of the number of reports received in a given year to the number of people resident in the US for that year multiplied by one million. So if the total number of reports for a given year remains as that of the previous year and the population increases in size the ratio for the given year will be smaller than that of the previous year). All things being equal, the increasing trend means either adverse events are occurring more often than before or awareness of the need to report adverse events is increasing amongst the US population, given that adverse events are not reported as often as they occur [9] [11]. 
Table 1. Yearly and overall values for death, other outcomes and all reported adverse events.

\begin{tabular}{cccccccc}
\hline Year & $\begin{array}{c}\text { Total } \\
\text { (All Events) }\end{array}$ & $\begin{array}{c}\text { Number of } \\
\text { Deaths }\end{array}$ & $\begin{array}{c}\text { Deaths } \\
\%\end{array}$ & $\begin{array}{c}\text { Other } \\
\text { Outcomes } \\
\%\end{array}$ & $\begin{array}{c}\text { Total } \\
\text { (excluding cases } \\
\text { with missing } \\
\text { Death values) }\end{array}$ & $\begin{array}{c}\text { Deaths } \\
\%\end{array}$ & $\begin{array}{c}\text { Other } \\
\text { Outcomes } \\
\%\end{array}$ \\
\hline 2013 & 746,182 & 75,028 & 10.1 & 89.9 & 430,356 & 17.4 & 82.6 \\
2014 & 793,254 & 84,037 & 10.6 & 89.4 & 471,903 & 17.8 & 82.2 \\
2015 & $1,219,741$ & 103,564 & 8.5 & 91.5 & 599,922 & 17.3 & 82.7 \\
2016 & $1,165,586$ & 95,410 & 8.2 & 91.8 & 590,399 & 16.2 & 83.8 \\
2017 & $1,234,834$ & 114,140 & 9.2 & 90.8 & 654,246 & 17.4 & 82.6 \\
2018 & $1,554,866$ & 143,496 & 9.2 & 90.8 & 855,412 & 16.8 & 83.2 \\
Total & $6,714,463$ & 615,675 & 9.2 & 90.8 & $3,602,238$ & 17.1 & 82.9 \\
\hline
\end{tabular}

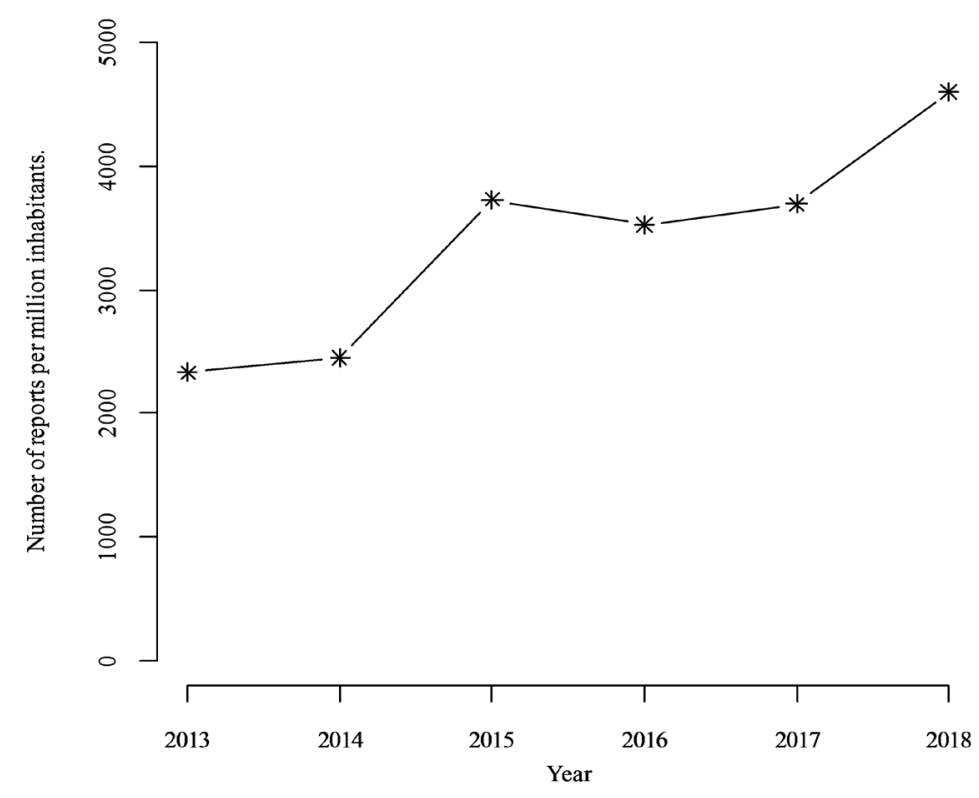

Figure 1. Line chart showing the number of reports per millon inhabitants against time, 2013-2018.

\subsection{Patient Outcome}

For the six-year period under consideration, a whopping $46.4 \%(3,112,225)$ of the total number of reports of 6,714,463 had missing patient outcomes (Table 2(a)). Of the remaining $3,602,238$ cases with valid patient outcome values, 615,675 (17.1\%) had an outcome of death (Table 2(b)) and in 155,671 (4.3\%) of the cases the outcome was life-threatening. A high proportion of 40.0\% (1,440,665 reports) of the cases with valid patient outcomes were serious enough to warrant hospitalisation or extension of stay at the hospital. The need to take action to avert permanent impairment occurred in $11931(0.3 \%)$ of the cases. Cases that resulted in disability, congenital anomaly and other outcomes accounted for 113,053 (3.1\%), $23,231(0.6 \%)$ and 2,209,643 (61.35\%) of the reports respectively. One is reminded of the fact that the categories of patient outcomes are not mutually exclusive and therefore it is possible for the total percentage for patient outcome to exceed 100. 
Table 2. (a) Patient outcomes, 2013-2018; (b) Patient outcomes, 2013-2018; (c) Percentages for patient outcomes calculated with number of non-missing cases as denominator, 2013-2018.; Percentages for Patient Outcomes calculated with number of all cases as denominator, 2013-2018.

(a)

\begin{tabular}{ccccccc}
\hline \multicolumn{5}{c}{ Cases } \\
\hline \multicolumn{2}{r}{ Valid } & \multicolumn{3}{c}{ Missing } & \multicolumn{2}{c}{ Total } \\
\hline \multirow{2}{*}{ Count } & $\%$ & Count & $\%$ & Count & $\%$ \\
$3,602,238$ & 53.6 & $3,112,225$ & 46.4 & $6,714,463$ & 100 \\
\hline
\end{tabular}

(b)

\begin{tabular}{lcc}
\hline \multicolumn{1}{c}{ Outcome } & Cases & Percentage (\%) \\
\hline Death (DE) & 615,675 & 17.1 \\
Life-Threatening (LT) & 155,671 & 4.3 \\
Hospitalization-Initial or Prolonged stay (HO) & $1,440,665$ & 40.0 \\
Disability (DS) & 113,053 & 3.1 \\
Congenital Anomaly (CA) & 23,231 & 0.6 \\
Required Intervention to Prevent Permanent & 11,931 & 0.3 \\
Impairment/Damage (RI) & $2,209,643$ & 61.3 \\
Other (OTH) & & \\
\hline
\end{tabular}

(c)

\begin{tabular}{cccccccc}
\hline \multicolumn{7}{c}{ Patient Outcomes } \\
\hline Year & DE & LT & HO & DS & CA & RI & OTH \\
\hline 2013 & 17.4 & 4.4 & 39.7 & 3.7 & 0.7 & 0.5 & 56.1 \\
2014 & 17.8 & 4.2 & 40.8 & 3.7 & 0.6 & 0.4 & 56.8 \\
2015 & 17.2 & 3.7 & 40.9 & 3.1 & 0.6 & 0.5 & 60.8 \\
2016 & 16.1 & 4.0 & 40.6 & 2.9 & 0.6 & 0.2 & 62.2 \\
2017 & 17.4 & 4.4 & 38.7 & 2.8 & 0.5 & 0.2 & 63.9 \\
2018 & 16.7 & 4.8 & 39.4 & 2.8 & 0.6 & 0.1 & 64.1 \\
Average & 17.1 & 4.2 & 40.0 & 3.1 & 0.6 & 0.3 & 60.6 \\
\hline
\end{tabular}

(d)

\begin{tabular}{cccccccc}
\hline \multicolumn{7}{c}{ Patient Outcomes } \\
\hline Year & DE & LT & HO & DS & CA & RI & OTH \\
\hline 2013 & 10.1 & 2.6 & 22.9 & 2.1 & 0.4 & 0.3 & 32.4 \\
2014 & 10.6 & 2.5 & 24.3 & 2.3 & 0.4 & 0.2 & 33.8 \\
2015 & 8.5 & 1.8 & 20.1 & 1.5 & 0.3 & 0.3 & 29.9 \\
2016 & 8.2 & 2.1 & 20.6 & 1.5 & 0.3 & 0.1 & 31.5 \\
2017 & 9.2 & 2.3 & 20.5 & 1.5 & 0.3 & 0.1 & 33.9 \\
2018 & 9.2 & 2.7 & 21.7 & 1.6 & 0.3 & 0.1 & 35.3 \\
Average & 9.3 & 2.3 & 21.6 & 1.7 & 0.3 & 0.2 & 32.8 \\
\hline
\end{tabular}


Figure 2(a), Figure 2(b) and Figure 3 were produced to assess the trend in the annual number of cases with an outcome of death relative to the annual total number of cases and the annual total number of non-missing cases, and whether or not the problem of cases with missing patient outcome has an effect on the trend in the proportion of cases that resulted in death over time. Figure 2(a) and Figure 2(b) show that, overall, there is an increasing trend in the annual total number of deaths reported and the drop in the number of deaths reported in 2016 is consistent with the drop in the number of all reports received in 2016 relative to that of 2015 for both Figure 2(a) and Figure 2(b). Comparing the bars plotted with the proportion of deaths determined from the number of all annual reported cases (lightblue) with that determined from the number of annual non-missing cases (mistyrose) (Figure 3), one could deduce that the problem of missing patient

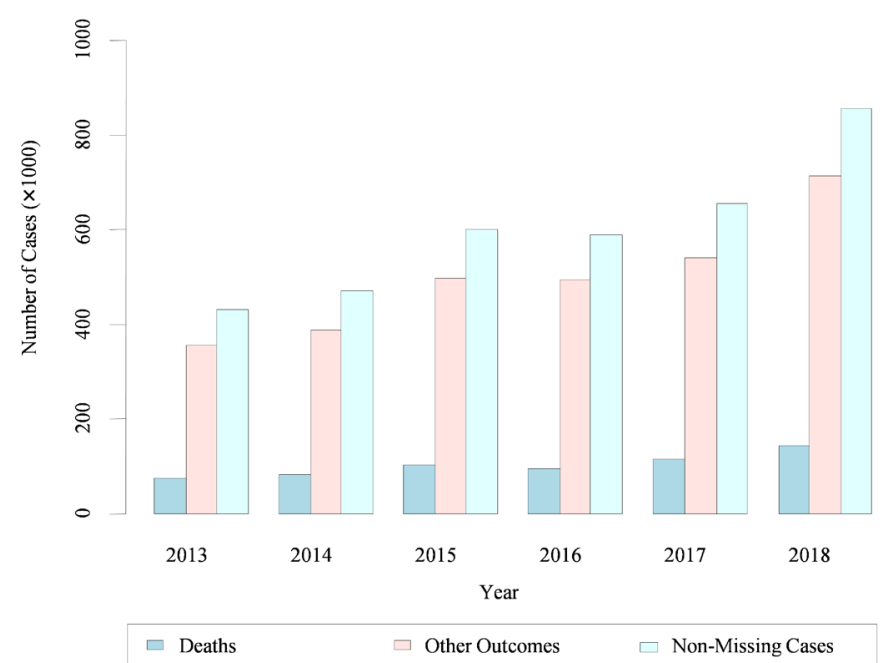

(a)

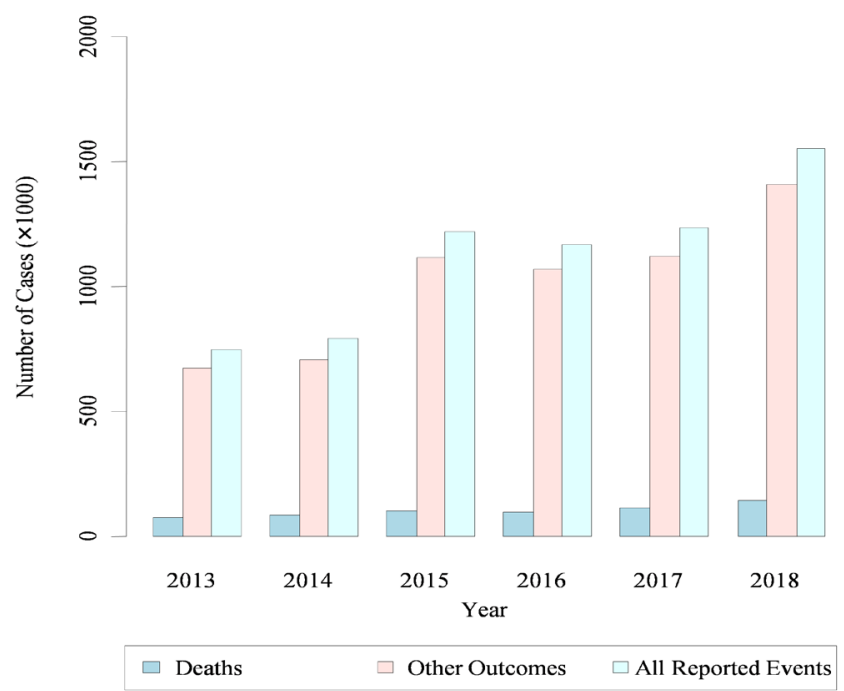

(b)

Figure 2. (a) Multiple bar chart comparing the trends in deaths, other outcomes, non-missing cases; (b) multiple bar chart comparing the trends in deaths, other outcomes and all reported events. 


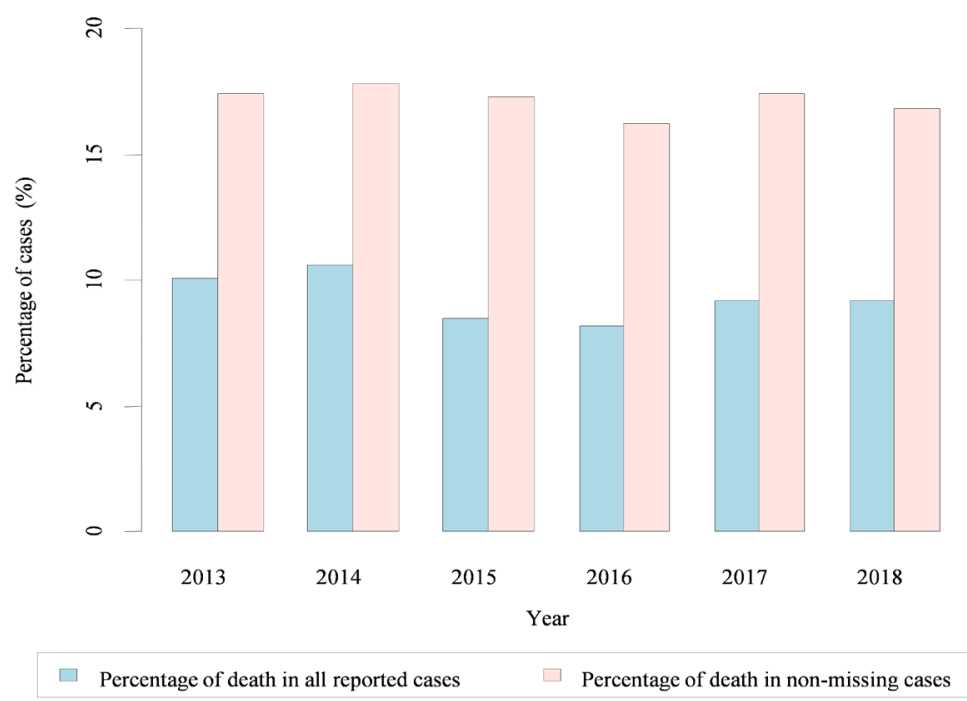

Figure 3. Multiple bar chart comparing the trends in the percentage of deaths for all reported events and for the non-missing cases.

outcome values did not have significant effect on the proportion of deaths reported annually for the period 2013 to 2018 .

Over the period under consideration, proportion of reports with an outcome of death for cases for which the patient outcome was specified assumed a high of $17.8 \%$ (2014) and a low of $16.1 \%$ (2016), with the average for the period standing at $17.1 \%$ (Table $2(\mathrm{c})$ ). The corresponding values when the denominator is changed to number of all annual cases is $10.6 \%$ (2014), 8.2\% (2016) and 9.3\% respectively. The proportion of cases with non-missing patient outcomes that resulted in the subject being hospitalised or staying at hospital for an extended period assumed a high of $40.9 \%$ (2015) and a low of $38.7 \%$ (2017) with the average for the period being $40.8 \%$. The respective values when the denominator is changed to number of all annual cases are $24.3 \%$ (2014), 20.1\% (2015) and 21.6\% (Table 2(d)). The proportion for the other patient outcomes are presented in Table 2(c) and Table 2(d).

\subsection{Occupation of Reporters}

The occupation of the original reporter of an adverse event is required by the FDA (US), whether the report is made directly or not [17]. A proportion of $2.6 \%$ $(171,632)$ of the total cases of 6,714,463 examined for the period under consideration had the occupation of the original reporter to be missing (Table 3(a)). Non-health professionals (NHP: consumers, legal representatives) accounted for more than half $(52.2 \%)$ of the remaining 6,542,831 cases with health professionals (HP: Physicians, Pharmacists, Other Health-Professionals) accounting for the remaining $47.8 \%$ (Table 3(b)). Indeed non-health professionals dominated in the first four years of the six-year period under review, accounting for more than $50 \%$ of the reports in each of these years. The trend in the annual percentages suggests an upward trend in the proportion of reports originating from health professionals and a downward trend in the proportion of reports originating from non-health professionals (Figure 4). 
Table 3. Occupation of original reporters, 2013-2018.

(a)

\begin{tabular}{|c|c|c|c|c|c|}
\hline \multicolumn{6}{|c|}{ Cases } \\
\hline \multicolumn{2}{|c|}{ Valid } & \multicolumn{2}{|c|}{ Missing } & \multicolumn{2}{|c|}{ Total } \\
\hline Count & $\%$ & Count & $\%$ & Count & $\%$ \\
\hline $6,542,831$ & 97.4 & 171,632 & 2.6 & $6,714,463$ & 100 \\
\hline
\end{tabular}

(b)

\begin{tabular}{|c|c|c|}
\hline Occupation & Cases & Percentage (\%) \\
\hline Physician & $1,472,796$ & 22.5 \\
\hline Pharmacist & 448,488 & 6.9 \\
\hline Other Health-Professional & $1,202,234$ & 18.4 \\
\hline Lawyer & 93,377 & 1.4 \\
\hline Consumer & $3,325,936$ & 50.8 \\
\hline
\end{tabular}

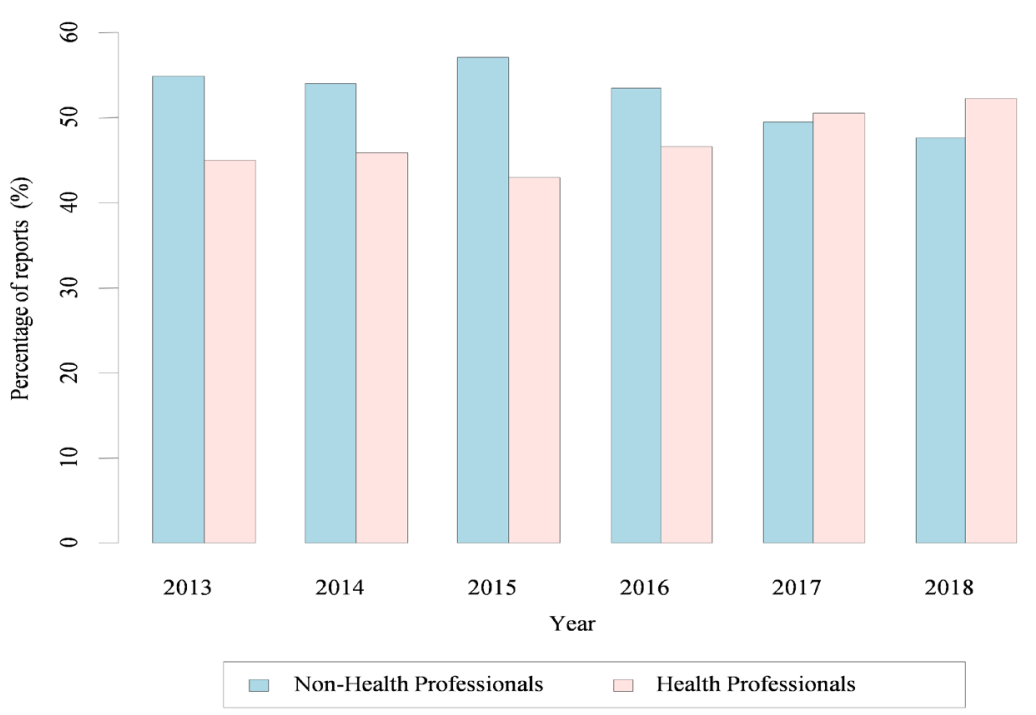

Figure 4. Percentage of non-health professionals and health professionals, 2013-2018.

\subsection{Types of Reports}

For the period under review, direct, expedited and periodic reports accounted for 303,285 (4.5\%), 3,120, 114 (46.5\%) and 3,291,064 (49.0\%) of the total number of cases respectively (Table 4 ). An examination of the annual percentages suggests that, overall, the proportion of reports coming from the direct source is increasing, even though there was a slight drop in the 2015 value relative to the 2014 value and it accounted for the least proportion of the reports in all the years under consideration. Expedited reports accounted for the highest proportion of the reports for the first two years of the period under review with periodic reports abruptly overtaking reports from the expedited source in 2015 and dominating in 2016 and 2017 before giving way to expedited reports in 2018 (Figure 5). Figure 5 shows that the proportion of reports from the periodic source is on the decline while that from the expedited source is on the increase. 


\subsection{Mode of Submission of Reports}

Over ninety-four percent $(94.2 \%, 6,327,914$ cases $)$ of the reports were submitted electronically with the rest $(5.8 \%, 386,549$ cases) submitted in hard copy (Table $5)$. Electronic submission was on the ascendancy until 2016; it contributed over $91 \%$ of the reports in 2013, reached over $95 \%$ in 2016 and then declined marginally in the last two years, but still accounting for about $94 \%$ of the reports.

\subsection{Sex of Subjects}

The sex of 711,989 (10.6\%) of the cases examined for the period under review were missing (Table 6(a)). The remainder of 6,002,474 cases is made up of $3,699,826$ (61.6\%) female cases and 2,302,648 (38.4\%) male cases (Table 6(b)). This result is congruent with that of the results for the 2007 to 2012 period in terms of the dominance of reports on female subjects for both the whole period and the annual situations, with females and males accounting for a little over $60 \%$ percent and a little below $40 \%$ of the reports respectively (Figure 6).

Table 4. Report types, 2013-2018.

\begin{tabular}{ccc}
\hline Type of report & Cases & Percentage (\%) \\
\hline Direct & 303,285 & 4.5 \\
Expedited & $3,120,114$ & 46.5 \\
Periodic & $3,291,064$ & 49.0 \\
\hline
\end{tabular}

Table 5. Report submission mode, 2013-2018.

\begin{tabular}{ccc}
\hline Electronic submission & Cases & Percentage (\%) \\
\hline No & 386,549 & 5.8 \\
Yes & $6,327,914$ & 94.2 \\
Total & $6,714,463$ & 100.0 \\
\hline
\end{tabular}

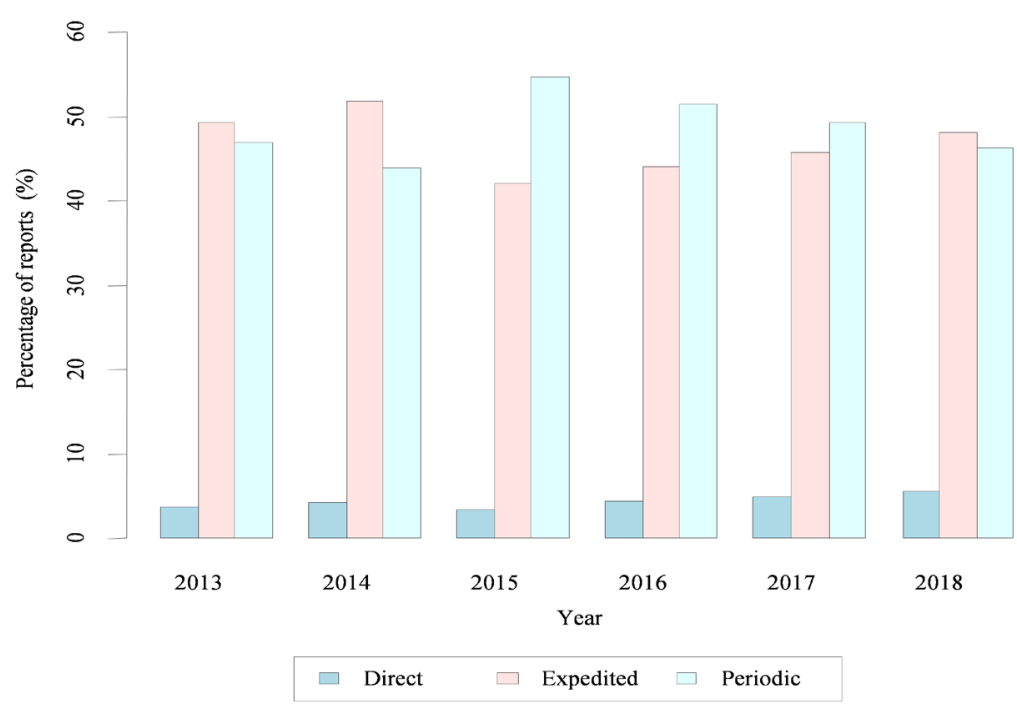

Figure 5. Percentage of report types, 2013-2018. 
Table 6. Sex of subjects, 2013-2018.

(a)

\begin{tabular}{|c|c|c|c|c|c|}
\hline \multicolumn{6}{|c|}{ Cases } \\
\hline \multicolumn{2}{|c|}{ Valid } & \multicolumn{2}{|c|}{ Missing } & \multicolumn{2}{|c|}{ Total } \\
\hline Count & $\%$ & Count & $\%$ & Count & $\%$ \\
\hline $6,002,474$ & 89.4 & 711,989 & 10.6 & $6,714,463$ & 100 \\
\hline
\end{tabular}

(b)

\begin{tabular}{ccc}
\hline Sex & Cases & Percentage (\%) \\
\hline Female & $3,699,826$ & 61.6 \\
Male & $2,302,648$ & 38.4 \\
\hline
\end{tabular}

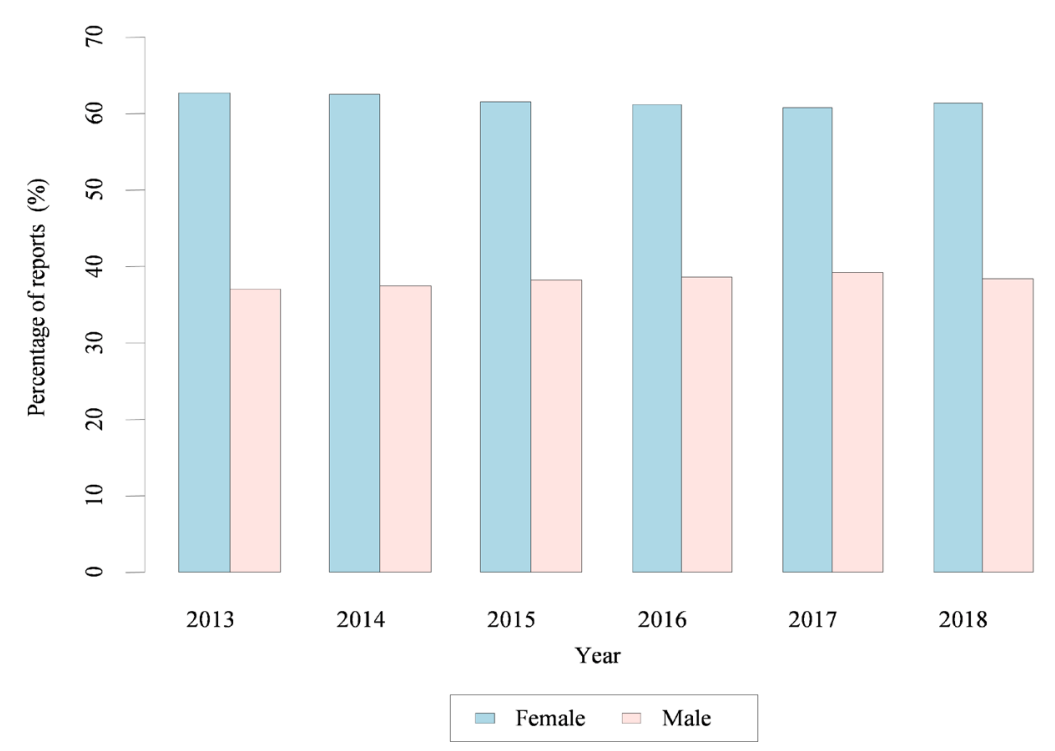

Figure 6. Percentage of reports on male and female subjects, 2013-2018.

\subsection{Age of Subjects}

Almost forty-two percent $(41.9 \%, 2,815,072$ cases) of the reports did not state the age of the subjects (Table 7 (a)). Of the remaining 3,899,391 cases, 205,217 (5.3\%) were in the age range $0-17,810,364(20.8 \%)$ were in the age range 18 44 , and 1,452,050 (37.2\%) and 1,431,760 (36.7\%) were in the age ranges 45 - 64 and 65 and over respectively (Table 7(b)). An examination of the annual values reveals a fluctuating pattern in the proportion of reports for which age was not specified with the least of $38.69 \%$ occurring in 2014 and the highest of $44.95 \%$ occurring in 2017. For the first four years of the period under review, the age group 45 - 64 accounted for the highest proportion of the reports, followed by the groups 65 and over, 18 - 44 and 0 - 17 in that order (Figure 7). In the last two years the percentage of cases within the age group 65 and over was more than that of the age group $45-64$. There is an increasing trend in the proportion of cases within the age ranges $0-17$ and 65 and over while the proportion of cases within the ranges $18-44$ and $45-64$ are on the decline (Figure 7). 
Table 7. Age of subjects, 2013-2018.

(a)

\begin{tabular}{ccccccc}
\hline \multicolumn{2}{c}{ Valid } & \multicolumn{3}{c}{ Cases } \\
\hline \multicolumn{2}{c}{ Missing } & \multicolumn{2}{c}{ Total } \\
\hline Count & $\%$ & Count & $\%$ & Count & $\%$ \\
\hline $3,899,391$ & 58.1 & $2,815,072$ & 41.9 & $6,714,463$ & 100 \\
\hline
\end{tabular}

(b)

\begin{tabular}{ccc}
\hline Age range & Cases & $\%$ \\
\hline$\leq 17$ & 205,217 & 5.3 \\
$18-44$ & 810,364 & 20.8 \\
$45-64$ & $1,452,050$ & 37.2 \\
$\geq 65$ & $1,431,760$ & 36.7 \\
\hline
\end{tabular}

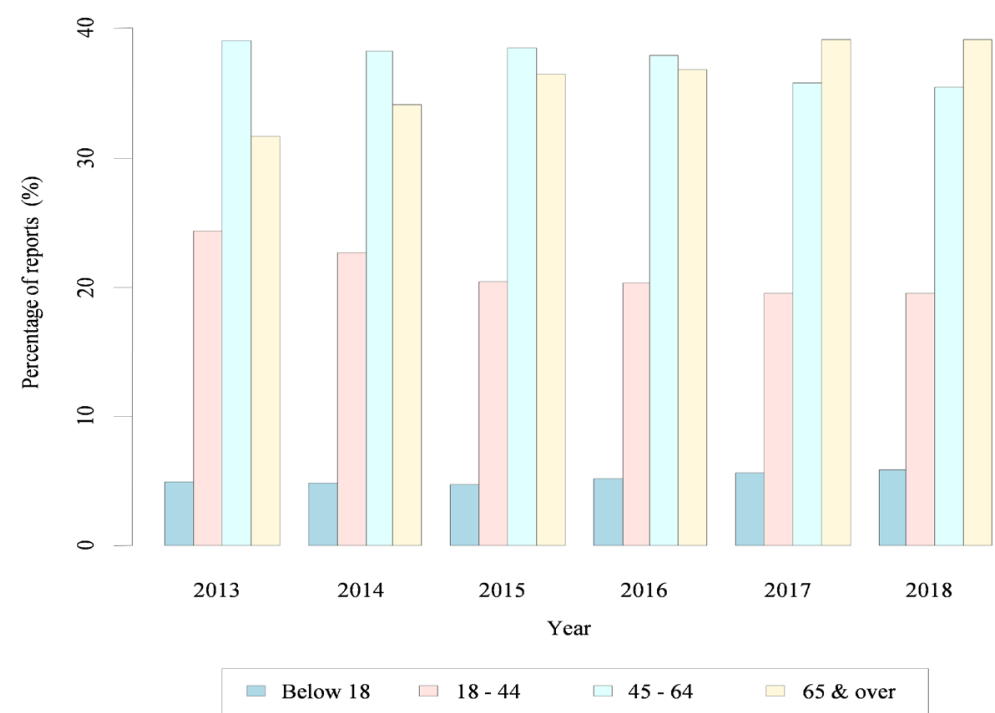

Figure 7. Percentage of reports for the various age groups, 2013-2018.

\subsection{Age and Sex Load of Subjects}

Table 8 shows the age and sex distribution of the cases for which both the age and sex were non-missing. The "proportion" $p$ of non-missing cases contributed by each of the age groups relative to their size in the overall US population is also presented in the table. To find $p$ for a particular age group, the number of non-missing cases in the age group in a particular year was divided by the number of people in that age group in the US population for that year. The resulting quotient was then multiplied by 10,000 to give the age group specific "proportion" for that year. The geometric mean of the age group specific "proportions" for the years under consideration gives the value of $p$ for the group [20]. Also presented in the table is the size, in percentage, of each of the age groups in the overall US population and the proportion of reports expected from the various age groups when the proportion of these age groups in the US population have been adjusted for potential drug use. 
Table 8. Age and sex load of adverse events, 2013-2018.

\begin{tabular}{|c|c|c|c|c|c|c|c|c|c|}
\hline \multirow{2}{*}{ Age group } & \multicolumn{2}{|c|}{ Female } & \multicolumn{2}{|c|}{ Male } & \multicolumn{2}{|c|}{ Total } & \multirow{2}{*}{$\begin{array}{c}\text { US Pop'n } \\
\text { Estimate }^{\zeta} \\
\%\end{array}$} & \multirow{2}{*}{$\begin{array}{c}\text { Exp'ted } \\
\text { cases }^{\xi} \\
\%\end{array}$} & \multirow{2}{*}{$\begin{array}{c}\text { Prop'n } \\
p\end{array}$} \\
\hline & Cases & $\%$ & Cases & $\%$ & Cases & $\%$ & & & \\
\hline$\leq 17$ & 96,446 & 2.5 & 100,195 & 2.6 & 196,641 & 5.1 & 22.9 & 10.1 & 4.4 \\
\hline $18-44$ & 548,070 & 14.2 & 254,315 & 6.6 & 802,385 & 20.9 & 34.5 & 25.8 & 11.8 \\
\hline $45-64$ & 893043 & 23.2 & 543,311 & 14.1 & $1,436,354$ & 37.3 & 29.3 & 40.0 & 24.6 \\
\hline$\geq 65$ & 815,406 & 21.2 & 598,289 & 15.5 & $1,413,695$ & 36.7 & 13.3 & 24.0 & 52.4 \\
\hline Total & $2,352,965$ & 61.1 & $1,496,110$ & 38.9 & $3,849,075$ & 100.0 & 100.0 & 100.0 & \\
\hline
\end{tabular}

${ }^{\zeta}$ Estimated from US population census values [25]; ${ }^{\xi}$ Population adjusted for potential drug use based on the 2011-2014 data on prescription drug use [26].

Table 8 shows that the number of male cases within the age group $0-17$ is slightly more than the number of female cases within the same age group. This is contrary to the case of the other age groups as they have more females than males. The proportion of the age group 0 - 44 (combining the groups 0 - 17 and 18 - 44) within the US population is bigger than the proportion of cases of adverse events reported on in this age group even when the former proportion has been adjusted (expected) for potential drug use. On the contrary, the proportion of the age group 45 and over (combining the groups 44 - 64 and 65 and over) within the US population is smaller than the proportion of cases of adverse events reported on in this age group even when the former proportion has been adjusted (expected) for potential drug use.

The proportion of cases of adverse events reported on for the age group 18 64 (combining the age groups 18 - 44 and 45 - 64) is less than the proportion of this age group in the overall US population ( 5.6 percentage point difference) and further less when the latter has been adjusted for potential drug use (7.6 percentage point difference, Table 8 and Figure 8 ). These observations are a marked departure from results obtained in the analysis reported in the paper covering the 2007 to 2012 period [16] and the results obtained by Moore et al. [18].

It is significant to note that the value of $p$ increases with age (down the table). A graphical version of the trend in the annual values of $p$ for the period under consideration is shown in Figure 9. In general, the values of $p$ for the various age groups appear to increase over time (this observation is also true for the 2007 to 2012 period). The bars for the various age groups for the year 2015 are higher than those of 2014 and those of the 2016 except for the group 0 - 17 where the bar for 2016 is higher than that of 2015.

\section{9. "Active Ingredients" (Drugs) Most Cited as Suspect in Adverse Events}

The top twenty (20) "active ingredients" (drugs), in descending order of frequency, most cited as suspect in causing adverse events for the periods 2013 to 2018 and 2007 to 2012 are as presented in Table 9. Each of the names that appear in Table 9 encapsulates all the medicinal forms (proprietary or brand products) 


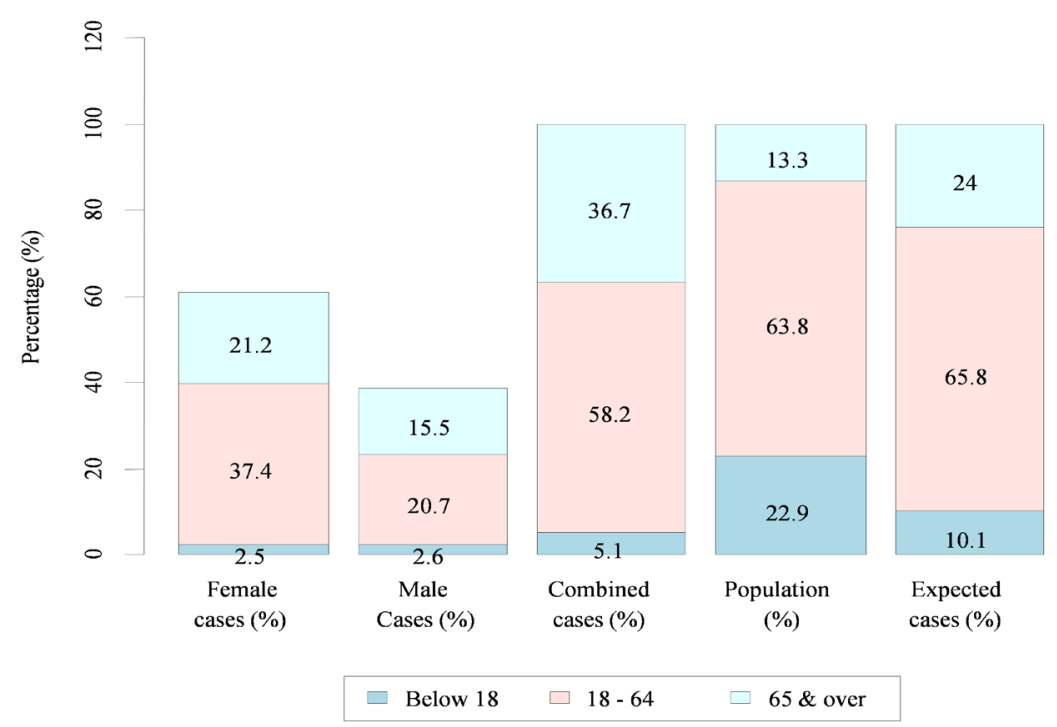

Figure 8. Age and gender load of reported adverse events associated with drug use for the period 2013-2018.

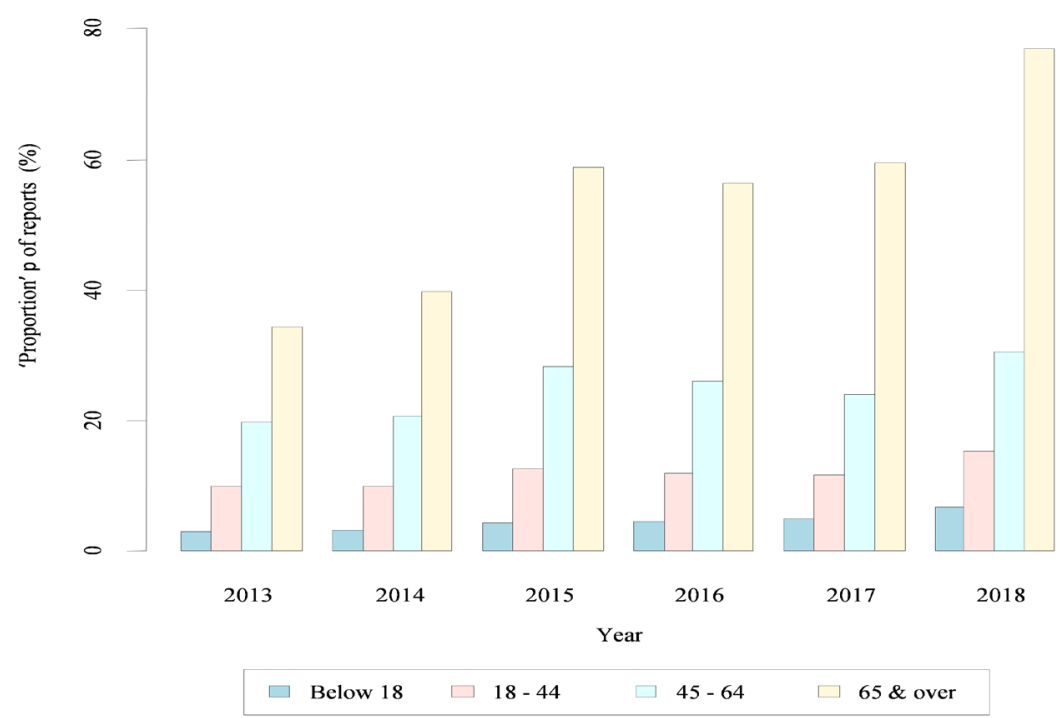

Figure 9. The "proportion" $p$ of the various age groups reported, 2013-2018.

that contain the same active ingredient. An examination of the table reveals that Etanercept and Adalimumab are the only drugs that had the same ranks, first and second respectively, in the period 2013 to 2018 as they did in the period 2007 to 2012 [16]. The rest either improved or declined in ranking. Indeed some of the drugs or some of their medicinal forms, were not on the market during the 2007 to 2012 period or were introduced towards the later end of the period and therefore did not make an appearance in the top twenty (20) list for the 2007 to 2012 period. Such drugs, which include Dimethyl Fumarate, Apremilast and Apixaban [27] [28] [29], are being widely used than before and have since assumed importance as principal suspect drugs in adverse events and were therefore able to make it to the top twenty (20) list for the 2013 to 2018 period. It is worthy of note that 
regulatory action could restrict the use of a medication and hence how often the medication is cited as a principal suspect in adverse drug event cases. It is also to be noted that the top twenty (20) drugs in the 2007 to 2012 period were still on the market in the US during the 2013 to 2018 period.

The level of missing patient outcomes (46.4\%) for the 2013 to 2018 period is higher than that of the 2007 to 2012 period (38.6\%) by 7.8 percentage points (Table 10). The change in the level of missing values for occupation, sex and age are $-6.0 \%, 1.8 \%$ and $0.1 \%$ respectively. Thus occupation is the only variable which saw a decrease in the level of missing values.

Table 9. Top twenty (20) active ingredients (drugs) most cited as suspect for causing adverse events, 2013-2018.

\begin{tabular}{|c|c|c|}
\hline \multirow{2}{*}{ Drug name } & \multicolumn{2}{|c|}{ Rank } \\
\hline & 2013-2018 & $2007-2012$ \\
\hline Etanercept & 1 & 1 \\
\hline Adalimumab & 2 & 2 \\
\hline Lenalidomide & 3 & 12 \\
\hline Denosumab & 4 & 63 \\
\hline Dianeal & 5 & 15 \\
\hline Rivaroxaban & 6 & 112 \\
\hline Dimethyl Fumarate & 7 & -- \\
\hline Natalizumab & 8 & 3 \\
\hline Interferon Beta-1a & 9 & 6 \\
\hline Apremilast & 10 & -- \\
\hline Levonorgestrel/Norgestrel & 11 & 4 \\
\hline Teriparatide & 12 & 19 \\
\hline Ambrisentan & 13 & 50 \\
\hline Rosiglitazone & 14 & 9 \\
\hline Evolocumab & 15 & -- \\
\hline Pregabalin & 16 & 13 \\
\hline Infliximab & 17 & 7 \\
\hline Fingolimod & 18 & 70 \\
\hline Sodium Oxybate & 19 & 213 \\
\hline Apixaban & 20 & -- \\
\hline
\end{tabular}

Table 10. Level of missing values as expressed as a percentage of total number of reports.

\begin{tabular}{ccccc}
\hline \multicolumn{5}{c}{ Variable } \\
\hline Period & Patient Outcomes & Occupation & Sex & Age \\
\hline $2007-2012$ & 38.6 & 8.6 & 8.8 & 41.8 \\
$2013-2018$ & 46.4 & 2.6 & 10.6 & 41.9 \\
Difference & 7.8 & -6.0 & 1.8 & 0.1 \\
\hline
\end{tabular}




\section{Discussion and Comments}

As seen in the results of the analysis presented above, the number of adverse events reported to the FDA (US) grew at an average annual rate of $15.8 \%$ for the 2013 to 2018 period. This growth rate is lower than the $22.1 \%$ per annum observed for the 2007 to 2012 period [16]; which may be indicating that the rate of reporting may have, on the whole, slowed down during the 2013 to 2018 period, compared to that of the 2007 to 2012 period. It could also be that in LAERS, the system did not recognise some of the duplicate reports as such, passing them off as non-duplicates which swelled the overall number of reports. If the foregoing is true, then the reorganisation of LAERS into FAERS has possibly led to a situation where duplicate reports are easy to identify and eliminate, resulting in the overall number of independent reports being relatively lower and hence the considerable drop in the average annual rate of growth of reported cases of adverse events from $22.1 \%$ in the 2007 to 2012 period to $15.8 \%$ in the 2013 to 2018 period. However, the estimated growth rate of 15.8 per annum of the 2013 to 2018 period may be a sign that awareness amongst the US populace of the need to report adverse events associated with the use of drugs is quite appreciable, albeit at a lower level than the six-year period before, when one considers the well-known issue of under-reporting [9] [11]. This view is borne out of the consideration that the estimated annual average growth rate of $15.8 \%$ in the number of cases reported for the 2013 to 2018 period is, though lower than that $(22.1 \%)$ of the previous six-year period, quite fast when compared to the US population's growth rate of 0.93\% per annum (based on the 2000 and 2010 US population census figures [30]).

It is worth noting that more reports were received for the 2013 to 2018 period than for the 2007 to 2012 period [16] as the total number of reports $(6,714,463)$ received for the 2013 to 2018 period is approximately 2.7 times the number of reports $(2,483,936)$ received for the 2007 to 2012 period, in spite of the slowing down of the rate of reporting (assuming the argument about ease of elimination of duplicates for the 2013 to 2018 period is untenable) as evidenced by the decrease in the average annual growth rate from $22.1 \%$ in the 2007 to 2012 period to $15.8 \%$ in the 2013 to 2018 period. Perhaps the average annual growth rate in the number of cases of adverse events reported in the 2013 to 2018 period may have been shored up by dramatic rise of $53.8 \%$ (see Table 1 or Figure 1 ) in the number of cases of adverse events reported in 2015 compared to that of 2014, resulting in the value of $15.8 \%$. Such sharp rise (53.8\%) in the number of reports in a relatively short period of one year compared to the average annual growth rate of $15.8 \%$ in the number of reports for the six-year study period of 2013 to 2018, may be responsible for the instability in the reporting rate of adverse events as noted in the introduction [13], which may arise from: i) the public reporting more often than they "usually" do as a result of becoming extra sensitive, if the media overly hype episodes of adverse events or ii) marketing activities of pharmaceutical 
concerns [9] [13] or iii) the introduction into the market of a new product with unsuspected side-effect(s) or sudden rise in the use of a drug for purposes other than indicated in the product information.

The fall in the number of reports received by the FDA in 2016, when compared to that of 2015, suggests an attempt may have been made to understand what motivated the sharp rise in the number of reports received in 2015 relative to that of 2014 and some form of regulatory action may have been taken to deal with the possible factor accounting for the remarkably high number of reports that year; and which resulted in the drop in the number of reports received in 2016.

Figure 2(a) and Figure 2(b) suggest the number of cases with an outcome of death increases as the overall number of cases reported increases. The results of the assessment of whether the issue of missing values could affect the proportion of cases reported to have resulted in death in the annual number of cases for 2013 to 2018 period agree with that of the 2007 to 2012 period and appear to suggest that the phenomenon of missing values is likely not to have any significant effect on the proportion of cases that are reported to have resulted in death. The rate of growth of the number of death which appeared to be increasing in the 2007 to 2012 period seem to have stabilized as the proportion of deaths relative to both the overall number of reports and the non-missing cases seem to hover around $9 \%$ and $17 \%$ respectively (Figure 3 ).

One could infer that the proportion of reported cases of adverse events that resulted in death and hospitalization (including those that warranted extension of hospital stay) were at least $8.2 \%$ and $20.1 \%$ respectively for the 2013 to 2018 period. These values are quite close to the respective values of $7.6 \%$ and $21.4 \mathrm{ob}-$ tained for the 2007 to 2012 period [16].

Non-health professionals (consumers or their legal representatives) appear to be as aware as health professionals (physicians, pharmacists, other health-professionals) on the need to report cases of ADEs if not better as, on the whole, they accounted for majority of the reports (52.2\%) submitted during the 2013 to 2018 period and dominated in the first four years of the period (Figure 4). Indeed in the 2007 to 2012 period reports from non-health professionals were dominant in three of the six-year period whiles the other three years saw reports from health professionals being in the majority [16].

Unlike the 2007 to 2012 period when expedited reports were in the majority in the overall number of reports and in each of the years in the period, the 2013 to 2018 period had periodic reports accounting for the majority in the overall number of reports and in three of the years in the period (2015-2017, Figure 5). As Figure 5 shows, the sharp rise in the total number of reports received by the FDA (US) in 2015 was largely due to the preponderance of periodic reports. Periodic reports concern serious adverse events that are captured in the product information [19]. Their multiplicity in 2015 may have arisen from the introduction into the market of a product whose unsuspected side-effect(s) is/are reminiscent of adverse reaction(s) of drugs already on the market, making early detection and 
timely intervention difficult or there may have been a breach of the restriction on some medications with known side-effect(s), leading to their abuse and hence the sudden increase in the number of periodic reports or unexpected upsurge in the usage of an established drug (whose side-effects are known) for purposes other than indicated as pointed out above.

Consistent with the prognosis made in the report covering the 2007 to 2012 that submission of reports via the internet will continue to rise, electronic submission reached a high of $95.6 \%$ in 2016 and appear to have levelled off at around the $94 \%$ mark. Just as the advent of email has not obliterated the use of paper communication, submission of reports in hard copy will persist for some time but will be become less and less important. As observed in the report covering the 2007 to 2012 period, the focus now should be on how to maximise accurate reporting as it is the best way of ensuring quality data [16] [31], so that the full potential of the spontaneous reporting system can be reaped.

Males and females accounted for a little below two-fifth (38.4\%) and a little over three-fifth (61.6\%) of the reports respectively in the 2013 to 2018 period (Table 6 ). This puts the ratio of number of reports on males to that on females at roughly $2: 3$, which is at variance with the roughly $1: 1$ ratio of male $(49.2 \%)$ to female (50.8\%) [30] in the overall sex structure of the US population and raises the same question as was observed in the report covering the 2007 to 2012 period for the reasons presented in the forgoing: namely, whether females are predisposed to adverse events more than men? As information from the National Center for Health Statistics (US) suggests, the female population has a higher propensity for drug use than male population (at least one prescription drug use in the last 30 days: male $43.4 \%$, female 53.9\%) [26]. Does this information completely answer the question above? The respective expected percentages for male and female reports are $43.8 \%$ and $56.2 \%$ (when the US male and female population proportions have been adjusted for potential drug use). Thus the observed report proportions of $38.4 \%$ for males and $61.6 \%$ for females falls short of and exceeds the expected respectively. Either adverse events involving men are less likely to be reported or women are more susceptible to adverse events. This calls for further investigation, especially so when one considers the fact of the consistency between the results obtained for the 2007 to 2012 and 2013 to 2018 periods. Again, as observed in the paper covering the 2007 to 2012 period [16], and contrary to the observation that, overall, female cases outnumber male cases, male cases outnumber female cases in the age group 0 - 17 for the 2013 to 2018 period; and this reechoes the issue of whether males below the age of 18 are more susceptible to adverse events than their female counterparts in the US population, since males and females in this age range have roughly the same (22.74\%) [26] likelihood of drug use, and if so what could be responsible for it?

The results from the analysis for the 2013 to 2018 period show that the percentage of adverse events reports on the age groups $0-17$ years and 65 years or older are comparatively smaller and comparatively greater respectively, relative 
to the size, in percentage, of these age groups in the overall US population, even when the latter percentage has been adjusted for potential drug use. The forgoing observation when taken with the fact that the value of $p$ increases with age (Table 8), also appear to suggest that the prospect of experiencing adverse events increases as one gets older, as was also deduced from the results obtained for the 2007 to 2012 period [16]. Indeed an examination of the yearly $p$ values for the 2013 to 2018 period, as depicted by Figure 9, reveals a general increasing trend over time (also true for the 2007 to 2012 period). What could be inferred from this is that the fraction of each of these age groups reported to have been involved in adverse drug events are increasing over time. Is the prospect of experiencing an adverse event on the increase amongst the US populace in general, and if so what could be the cause of this; or awareness of the need to report adverse events associated with drug use is on the increase, albeit at a lower rate than the 2007 to 2012 period, given the issue of under-reporting [9] [11], for which reason the various age groups are contributing adverse events reports at an increasing rate? While the $p$ values for the age groups 0 - 17, 18 - 44 and 45 - 64 for the 2013 to 2018 period are roughly two-and-half times (2.59, 2.46, 2.44 respectively) that of the respective values for the 2007 to 2012 period, the $p$ value for the age group 65 and over for 2013 to 2018 is more than three times (3.21) that of the 2007 to 2012 period, which may be an indication that the prospect of experiencing an adverse event is increasing at an even higher rate amongst the 65 years or older group than the rest of the populace.

As Table 10 shows, of the variables prone to missing values, occupation is the only variable which saw a decrease in the level of missing values when the values of the 2007 to 2012 period are compared with that of the 2013 to 2018 period. Patient outcomes, sex and age saw increases in the level of missing values associated with them, indicating that the condition of the problem of missing values is in general not improving.

One is reminded that the drugs appearing in Table 9 are only regarded as suspects as far as the adverse drug events for which they were cited are concerned, as their association with the adverse events may be coincidental or the adverse event is a symptom of the disease under treatment or that of a disease that is yet to be recognized. Drug-drug interaction or another drug other than cited may have been responsible for the adverse event [4] [9]. An expert view born out of an examination of the evidence presented by the circumstances of an adverse event by professionals who are adept at adverse event causality assessments is required to come the conclusion that a drug really caused the adverse event. However, that drugs can cause adverse events is not in doubt and some of the drugs appearing in Table 9 may have made it to the table because they cause a few serious adverse events or they cause quite a number of less serious adverse events that show up together when the drug is being used, that the user is compelled to report fearing something ominous might happen, given that adverse events are generally under-reported [9] [11]. 


\section{Conclusions}

The objectives of the study reported in this paper were to: i) explore the trends in the variables involved with the adverse events problem in the 2013 to 2018 period and compare these trends with that found in the study covering the 2007 to 2012 period; ii) determine whether or not the level of missing variable values in the 2013 to 2018 period is lower than, the same or higher than it was in the 2007 to 2012 period; iii) find out how the first twenty principal suspect drugs most cited to be involved in adverse events occurring during drug use in the 2013 to 2018 period compare with that of the 2007 to 2012 period. One notable trend, which seems to present both good and bad news, is the upward trend in the number of reports submitted per one million people, as depicted by Figure 1. As observed in Section 4, it seems to indicate that, there is an appreciable level of awareness amongst the US populace (though lower than that of the previous six-year period, if the argument about the prospect of easy identification and elimination of duplicate reports as a result of the transition from LAERS to FAERS, leading to lower number of independent reports is insignificant) of the need to report adverse events; occasioning a relatively higher rate of growth in the number of reports submitted compared with the growth rate of the US population, when one considers that adverse events are not reported as often as they occur [9] [11]. The need to sensitise the US population on the importance of reporting adverse events is all the more pressing as a comparison of the rate of growth (15.8\%) of the number of reports for the 2013 to 2018 period with that (22.1\%) of 2007 to 2012 period indicate a slacking of the rate at which adverse events are reported or some degree of indifference is creeping amongst the US populace in respect of the need to report adverse events. It could well be that the transition from LAERS to FAERS has made the adverse event reporting scheme in the US more effective at dealing with duplicate reports, which is the reason the average annual rate of growth in the number of reports dropped from $22.1 \%$ in the 2007 to 2012 period to $15.8 \%$ in the 2013 to 2018 period. If this is the case, then the transition has been very helpful and the drop in the average annual rate of growth in the number of cases reported cannot be attributed to a slaking of the rate at which adverse events are reported nor can it attributed to a creeping indifference amongst the US populace on the need to report adverse events. The situation will be clearer as data from the FAERS is assessed in the years ahead.

Though available data suggest females have a higher propensity for drug use than males the consistency of the results of the analysis for both the 2007 to 2012 and 2013 to 2018 periods seem to suggest that the relatively higher number of reports on females compared to that of males is not solely due to the higher propensity of females for drug use. Further investigation aimed at establishing whether females are relatively more susceptible to adverse events associated with drug use or events involving males are less likely to be reported is required.

There is the need to ascertain why the prospect of adverse drug experiences seems to be on the increase amongst all the age groups in the US population as 
evidenced by the increasing trend in the value of $\mathrm{p}$. It is known that age plays a role in adverse drug experiences [2] [3]. What is new in this research is what appears to be a higher rate of increase in susceptibility to adverse drug effects within the 65 and older age group as was pointed out in the discussions.

The high levels of missing values in the case of some of the variables (as seen in the results of the analysis and further elucidated in the discussions) and the description of adverse events in terms that do not fully depict what happened such as "overdose", "off label use", "adverse event" and "multiple injuries", as a listing of the descriptions shows, lend credence to the phenomena of inaccurate reporting mentioned in the literature. Data of sound integrity is required to deal with the difficulties associated with the use of drugs. The problem of partial or inaccurate reporting such as reported above makes it difficult to fully characterise the irregularities associated with the use of drugs. More has to be done to sensitise the public on the need to do accurate reporting, if the lingering concern of inaccurate reporting is to be curtailed.

Also, though the trends observed in the analysis for the period 2013 to 2018 are in many respects similar to that observed for the period 2007 to 2012, there is nonetheless substantial differences in the observations in the two periods, which makes it imperative to continually examine SRS data, so that any emerging drug safety threats can be dealt with expeditiously.

While one cannot generalise the findings of this study, it could be argued that the problems of adverse events associated with drug use identified with the US are likely to be more or less the same for countries of comparable health delivery and regulatory sophistication and worse for countries with low literacy rates, flimsy ADR reporting systems or regulatory regimes, as the FDA (US) is arguably one of the most progressive drug regulatory bodies.

\section{Conflicts of Interest}

The author declares no conflicts of interest regarding the publication of this paper.

\section{References}

[1] Food and Drugs Administration (2018) Questions and Answers on FDA's Adverse Event Reporting System (FAERS).

https://www.fda.gov/Drugs/GuidanceComplianceRegulatoryInformation/Surveillan ce/AdverseDrugEffects/default.htm

[2] Drugs.com (2018) Drug Side Effects. https://www.drugs.com/sfx/

[3] Smith Marsh, D.E. (2018) Overview of Adverse Drug Reactions. Merck Manual, Merck and Company, Inc.

https://www.merckmanuals.com/home/drugs/adverse-drug-reactions/overview-ofadverse-drug-reactions

[4] Pirmohamed, M., Breckenridge, A.M., Kitteringham, N.R. and Park, B.K. (1998) Adverse Drug Reactions. British Medical Journal, 316, 1295-1298.

https://doi.org/10.1136/bmj.316.7140.1295 
[5] Davis, S., King, B. and Raine, J. M. (2007) Spontaneous Reporting-UK. In: Mann, R.D. and Andrews, E.B., Eds., Pharmacovigilance, 2nd Edition, John Wiley and Sons Ltd, Chichester, UK, 199-215. https://doi.org/10.1002/9780470059210.ch15

[6] Moore, T.J., Psaty, B.M. and Furberg, C.D. (1998) Time to Act on Drug Safety. Journal of American Medical Association, 279, 1571-1573. https://doi.org/10.1001/jama.279.19.1571

[7] Dumouchel, W. (1999) Bayesian Data Mining in Large Frequency Tables, with an Application to FDA Spontaneous Reporting System. The American Statistician, 53, 177-190. https://doi.org/10.1080/00031305.1999.10474456

[8] Evans, S.J.W. (2000) Pharmacovigilance: A Science or Fielding Emergencies. Statistics in Medicine, 19, 3199-3209.

https://doi.org/10.1002/1097-0258(20001215)19:23<3199::AID-SIM621>3.0.CO;2-Q

[9] Rawlins, M.D., Fracchia, G.N. and Rodriguez-Farre, E. (1992) EURO-ADR: PharMacovigilance and Research (A European Perspective). Pharmacoepidemiology and Drug Safety, 1, 261-268. https://doi.org/10.1002/pds.2630010508

[10] Medicines and Healthcare Products Regulatory Agency. How the MHRA Monitors the Safety of Medicines.

https://assets.publishing.service.gov.uk/government/uploads/system/uploads/attach ment_data/file/403099/Pharmacovigilance__how_the_MHRA_monitors_the_safet Y_of_medicines.pdf

[11] Alvarez-Requejo, A., Carvajal, A., Bergaud, B., Moride, Y., Vega. T. and Martin Arias, L.H. (1998) Under-Reporting of Adverse Drug Reactions: Estimate Based on a Spontaneous Reporting Scheme and a Sentinel System. European Journal of Clinical Pharmacology, 54, 483-488. https://doi.org/10.1007/s002280050498

[12] Stephenson, W.P. and Hauben, M. (2007) Data Mining for Signals in Spontaneous Reporting Databases: Proceed with Caution. Pharmacoepidemiology and Drug Safety, 16, 359-365. https://doi.org/10.1002/pds.1323

[13] Bate, A. and Evans, S.J.W. (2009) Quantitative Signal Detection Using Spontane-ous ADR Reporting. Pharmacoepidemiology and Drug Safety, 18, 427-436. https://doi.org/10.1002/pds.1742

[14] Food and Drugs Administration (2018) FDA Adverse Event Reporting System (FAERS): Latest Quarterly Data Files.

https://www.fda.gov/drugs/questions-and-answers-fdas-adverse-event-reporting-sy stem-faers/fda-adverse-event-reporting-system-faers-latest-quarterly-data-files

[15] Baah, E.M. (2018) Pharmacovigilance: There Is a Need for All to Get Involved! Asian Journal of Research in Medical and Pharmaceutical Sciences, 5, 1-11. https://doi.org/10.9734/AJRIMPS/2018/44156

[16] Baah, E.M. (2019) Analysis of Adverse Events Reports Submitted to the Food and Drugs Administration of the United States of America (2007-2012). Asian Journal of Research in Medical and Pharmaceutical Sciences, 8, 1-17. https://doi.org/10.9734/ajrimps/2019/v8i1-230133

[17] Food and Drugs Administration (2018) FDA Adverse Event Reporting System (FAERS): Latest Quarterly Data Files-faersasciyearquarter/ANC_NTS.pdf. https://www.fda.gov/Drugs/GuidanceComplianceRegulatoryInformation/Surveillan ce/AdverseDrugEffects/ucm082193.htm

[18] Moore, T.J., Cohen, M.R. and Furberg, C.D. (2007) Serious Adverse Drug Events Reported to the Food and Drugs Administration, 1998-2005. Journal of American Medical Association, 167, 1752-1759. https://doi.org/10.1001/archinte.167.16.1752

[19] Food and Drugs Administration (2019) Code of Federal Regulations Title 21. 
https://www.accessdata.fda.gov/scripts/cdrh/cfdocs/cfcfr/CFRSearch.cfm?fr=310.305

[20] Baah, E.M. (2014) Analysis of Data on Spontaneous Reports of Adverse Events Associated with Drugs. Ph.D. Thesis, University of Glasgow, Glasgow, Scotland, UK.

[21] Mason, R.D., Lind, D.A. and Marchal, W.G. (1999) Statistical Techniques in Business and Economics. 10th Edition, Irwin/McGraw-Hill, Boston, MA.

[22] R Core Team (2019) R: A Language and Environment for Statistical Computing. R Foundation for Statistical Computing, Vienna, Austria. http://www.R-project.org/

[23] SAS Institute Inc. (2012) SAS Software. SAS Institute Inc., Cary, NC.

[24] Microsoft Corporation. MS Excel (2013) [Computer Software]. Microsoft Corporation, NE, Redmond, WA.

[25] Census Bureau (2018) Population Estimates-Intercensal Data Sets, US Census Bureau, Population Division, Washington DC 20233, 2010-2018.

[26] National Center for Health Statistics (2017) Health, United States 2016; With Chartbook on Long-Term Trends in Health. Technical Report, US National Center for Health Statistics (HCHS), Hyattsville, MD.

[27] Wikipedia (2020) Dimethyl Fumarate. https://en.wikipedia.org/wiki/Dimethyl_fumarate

[28] Wikipedia (2019) Apremilast. https://en.wikipedia.org/wiki/Apremilast

[29] Wikipedia (2020) Apixaban. https://en.wikipedia.org/wiki/Apixaban

[30] Census Bureau (2011) The Older Population: 2010; 2010 Census Briefs. https://www.census.gov/prod/cen2010/briefs/c2010br-09.pdf

[31] DuMouchel, W. (2007) Statistical Issues in the Analysis of Spontaneous Report Databases.

http://www.iom.edu/ /media/files/activity $\ \% 20$ files/research/drugforum/dumouche l.pdf 